\title{
CONF-9706/6--2 \\ SAND97.0108C \\ LIFE PREDICTION MODELING OF SOLDER INTERCONNECTS FOR ELECTRONIC SYSTEMS
}

\author{
Darrel R. Frear, Stephen N. Burchett, Michael K. Neilsen \\ Sandia National Laboratories \\ Albuquerque, NM
}

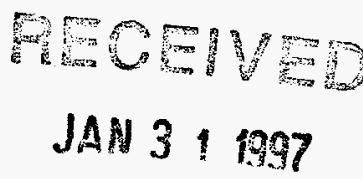

\begin{abstract}
A microstructurally-based computational simulation is presented that predicts the behavior and lifetime of solder interconnects for electronic applications. This finite element simulation is based on an internal state variable constitutive model that captures both creep and plasticity, and accounts for microstructural evolution. The basis of the microstructural evolution is a simple model that captures the grain size and microstructural defects in the solder. The mechanical behavior of the solder is incorporated into the model in the form of time-dependent, viscoplastic equations derived from experimental creep tests. The unique aspect of this methodology is that the constants in the constitutive relations of the model are determined from experimental tests. This paper presents the constitutive relations and the experimental means by which the constants in the equations are determined. The fatigue lifetime of the solder interconnects is predicted using a damage parameter (or grain size) that is an output of the computer simulation. This damage parameter methodology is discussed and experimentally validated.
\end{abstract}

\section{INTRODUCTION}

The long term reliability of electronic systems is often directly related to the lifetime of the solder interconnects in the package. The solder interconnect is no longer simply an electrical conductor but is also the structural material that holds the package together. The importance of the reliability of solder interconnects increases as the trend in the electronics industry moves toward surface mount technology, smaller joints, and finer pitch. One of the serious challenges to solder joint reliability is failures that are a result of thermomechanical fatigue. In an electronic package, the solder is typically constrained between two materials with different coefficients of thermal expansion. Fatigue failures originate as cyclic strain is applied to solder joints when the package is exposed to thermal fluctuations caused by either ambient temperature changes or by heat dissipation from the integrated circuit devices in the package. A thermal fatigue failure of a solder interconnect is shown in Figure 1.

The solder typically used for electronic applications is the near-eutectic $60 \mathrm{Sn}-40 \mathrm{~Pb}$ alloy. The metallurgy and time-strain-temperature behavior of this solder alloy is surprisingly complex and is an important onsigration in predicting the behavior and fatigue lifetime of the solde In the as-soldered condition, the $\mathrm{Sn}-\mathrm{Pb}$ alloy has a two phase microstructure. This structure is metastable due to the high interfacial energy that results from the large number of phase boundaries present. Under thermomechanical fatigue conditions, this microstructure evolves into a heterogeneously coarsened band where all subsequently applied strain is concentrated. The evolution of this heterogeneous coarsening is shown in Figure 2 where the initial, as-solidified, microstructure can be compared to the heterogeneously coarsened structure in a $60 \mathrm{Sn}-40 \mathrm{~Pb}$ solder joint. It is clearly important that the life prediction methodology that is used for near-eutectic $\mathrm{Sn}-\mathrm{Pb}$ solders capture the behavior of the material under conditions of thermomechanical fatigue. A methodology has been developed in which the microstructure, and microstructural evolution, are critical elements to the mathematical relations in a materials-based finite element methodology to predict the behavior of near-eutectic Sn$\mathrm{Pb}$ solders under conditions of thermomechanical fatigue.

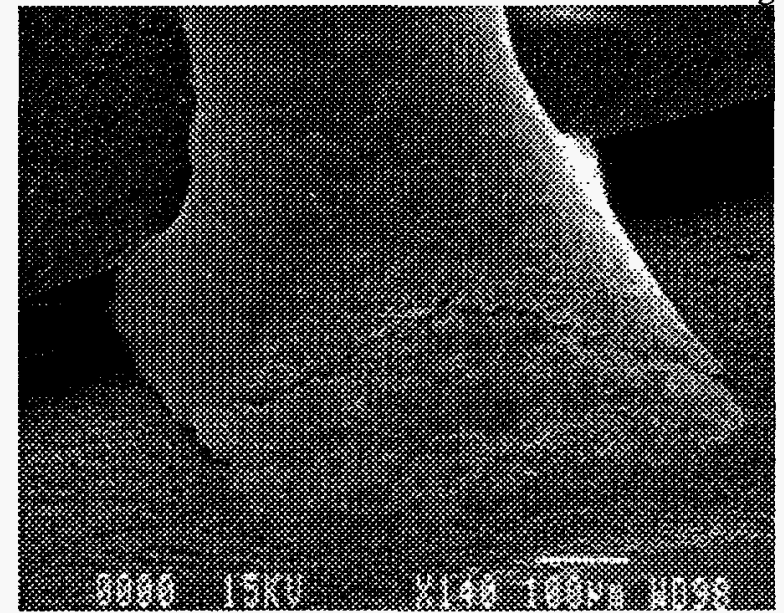

Figure 1 SEM image of a surface mount solder joint that failed due to thermomechanical fatigue.

\section{EXPERIMENTAL PROCEDURE}

Experimental tests have been developed to characterize the parameters needed to model the solder under thermomechanical fatigue conditions. The tests used to define the deformation behavior are uniaxial compression stress-strain tests and creep tests at a variety of stresses and temperatures. The results of these tests give the elastic plastic and time-dependent deformation behavior. 


\section{DISCLAIMER}

This report was prepared as an account of work sponsored by an agency of the United States Government. Neither the United States Government nor any agency thereof, nor any of their employees, make any warranty, express or implied, or assumes any legal liability or responsibility for the accuracy, completeness, or usefulness of any information, apparatus, product, or process disclosed, or represents that its use would not infringe privately owned rights. Reference herein to any specific commercial product, process, or service by trade name, trademark, manufacturer, or otherwise does not necessarily constitute or imply its endorsement, recommendation, or favoring by the United States Government or any agency thereof. The views and opinions of authors expressed herein do not necessarily state or reflect those of the United States Government or any agency thereof. 


\section{DISCLAMMER}

Portions of this document may be illegible in electronic image products. Images are produced from the best available original document. 
The results of these tests are stated mathematically in the form of a constitutive relation that defines the deformation and stress relaxation behavior of the solder.

Thermomechanical fatigue tests have been developed to cyclically impose strain and temperature on the solder joints while monitoring stress, electrical continuity and microstructural evolution. The results of the thermomechanical fatigue tests are used to characterize microstructural, and mechanical, evolution and to validate the simulation results.

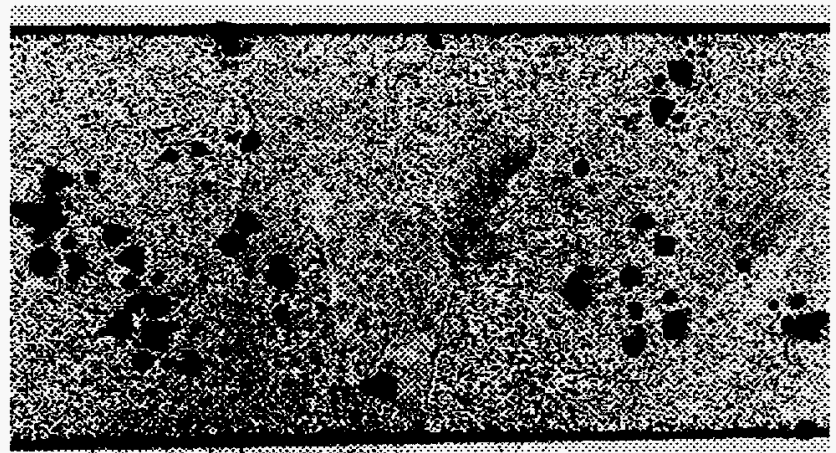

Figure 2a As-solidified $60 \mathrm{Sn}-4 \mathrm{OPb}$ solder.

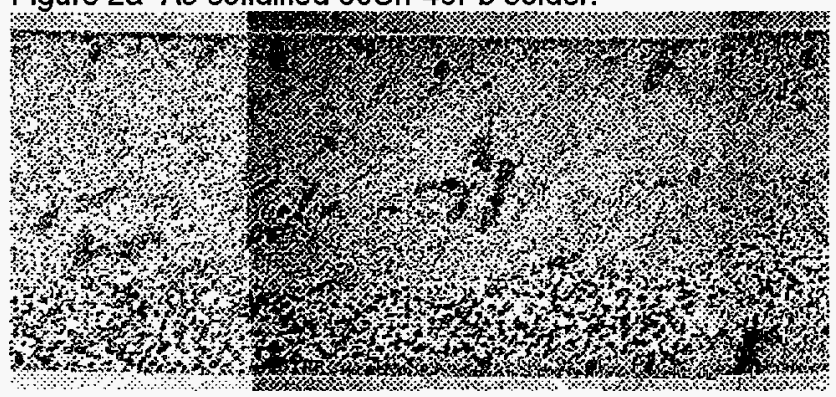

Figure 2b After thermomechanical fatigue. (Joint thickness is $0.254 \mathrm{~mm}$.)

The stress-strain tests, and the creep tests, were performed on bulk samples deformed in uniaxial compression. The $60 \mathrm{Sn}-40 \mathrm{~Pb}$ solder was melted at $220^{\circ} \mathrm{C}$ then poured directly into a chilled split mold. This was done in an effort to create the fine microstructure that is found in the small solder joints used in electronic packages. The ingots were machined into right circular cylinders 0.4 " diameter by 0.8 " in length. The mechanical tests were performed on a 155 kip servohydraulic test machine fitted with an environmental chamber and a $55 \mathrm{kN}$ load cell. The stress strain tests were performed in strain control at a strain rate of $2.1 \times 10^{-4} / \mathrm{sec}$. The creep tests were performed at $-55^{\circ}, 0^{\circ}, 23^{\circ}, 75^{\circ}$, and $125^{\circ} \mathrm{C}$. Each specimen was allowed to equilibrate in the environmental chamber for 30 minutes prior to testing. A compressive prestrain of approximately one percent was applied to the sample to insure contact between the specimen and the platens. Testing was performed in load control, with stresses ranging from 10 to $80 \mathrm{MPa}$ applied using a one second linear ramp. Platen displacement was monitored as a function of time. The minimum strain rate for each stress and temperature was subsequently determined from this strain-time data.

The thermomechanical fatigue tests were performed in a simple shear orientation. This procedure is described in greater depth elsewhere (Frear 1989, Frear, et al., 1993). A brief summary of the test method is given here. The specimen used to test solder joints is shown in the schematic drawing in Figure 3. The specimen consists of 18 electrically isolated solder joints that deform in shear when the specimen is pushed and pulled on its ends. The joints have a simple truncated spherical geometry. Strain is imposed upon the solder joints by a servohydraulic load frame operated under strain control. Thermal fluctuations are induced by a chamber that fits around the specimen in the load frame. Compressed air is heated and cooled by a commercial heating and cooling system and circulates around the specimen. The temperature extremes tested were $-55^{\circ}$ to $125^{\circ} \mathrm{C}$. The thermal cycle consists of a ramp in strain and temperature to the elevated temperature extreme a 3 minute hold period, a ramp down, and another 3 minute hold at the low temperature extreme. Failures are monitored electrically by monitoring spikes in resistance. The electrical data along with load, temperature, and strain are collected and stored on a computer. To examine the microstructure of the solder joints after testing, the samples were mounted and metallographically sectioned and polished.

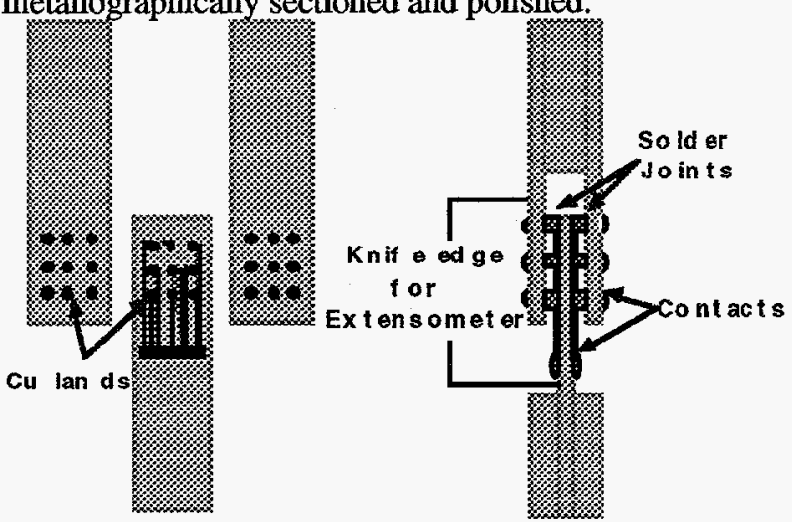

Figure 3 Thermomechanical fatigue test specimen.

\section{INTERNAL STATE VARIABLE CONSTITUTIVE MODEL}

A number of viscoplastic models have been developed for solder (Akay, et al., 1993; Pan and Winterbottom, 1990; Hacke, et al., 1993; Busso, et al., 1992; Guo, et al., 1992; Ling and Dasgupta, 1996; Ianuzzelli, et al., 1996; Syed, 1995; Frost and Howard, 1990; Knecht and Fox, 1990). Several of these models included an aspect of the microstructure such as an initial grain or phase size as a material constant that does not change during the simulations. The present viscoplastic model, developed to 
predict the behavior of solder interconnects under conditions of thermomechanical fatigue, differs from previous models because a measure of the microstructure is incorporated as an internal state variable that changes during the simulation. Characteristics of the microstructure are included as a damage parameter $(\lambda)$ that incorporates the vacancy concentration and the grain size of the solder. A scalar state variable is available in the model to capture isotropic hardening and recovery. A second-order state tensor is used to capture kinematic hardening and recovery. The heterogeneous coarsening of the microstructure is expected to have a significant effect on the state of the material, and a state variable which accounts for the reduction in flow stress with microstructural coarsening is incorporated following the Hall-Petch relationship.

The internal state variable constitutive model for the solder has the standard constitutive relationship:

$$
\dot{\sigma}=\mathbf{E}:\left(\mathbf{d}-\mathbf{d}^{\mathbf{i n}}\right)
$$

where $\sigma$ is the Cauchy stress in the unrotated configuration, $\mathrm{E}$ is the fourth-order isotropic elasticity tensor (derived from the Shear and Bulk Moduli), $\mathbf{d}$ is the total deformation rate in the unrotated configuration, and $d^{\text {in }}$ is the inelastic deformation rate in the unrotated configuration [Biffle and Blanford, 1994]. The inelastic deformation rate is given by:

$\mathbf{d}^{\mathrm{in}}=\frac{3}{2} \boldsymbol{\gamma n}=\frac{3}{2} \mathrm{f} \exp \left(\frac{-\mathrm{Q}}{\mathrm{RT}}\right)\left(\frac{\lambda_{0}}{\lambda}\right)^{\mathrm{p}} \sinh ^{\mathrm{m}}\left(\frac{\tau}{\alpha(\mathrm{c}+\hat{\mathrm{c}})}\right) \mathbf{n}$

where $\gamma$ is the magnitude of $d^{i n}, f, p, m$ and $Q$ are material parameters, $R$ is the gas constant $(1.987 \mathrm{cal} / \mathrm{Mol} \cdot \mathrm{K})$, and $\mathrm{T}$ is the absolute temperature. $\lambda$ is the microstructural parameter, $\lambda_{0}$ is its initial value. The effects of microstructural evolution are normalized in equation 2 by dividing the microstructural parameter by its initial value. $\alpha$ is a scalar function of the absolute temperature, $c$ and are state variables (defined below), and $\mathbf{n}$ is the normalized stress difference tensor which is given by:

$\mathbf{n}=\frac{\mathbf{s}-\frac{2}{3} \mathbf{B}}{\tau}$

where $\mathbf{s}$ is the stress deviator, $\mathbf{B}$ is the state tensor, which accounts for kinematic hardening, $\tau$ is the a von Mises effective stress, which is a scalar measure of the stress difference magnitude:

$\tau=\sqrt{\frac{3}{2}\left(s-\frac{2}{3} B\right):\left(s-\frac{2}{3} B\right)}$

The constants in equation 2 can be defined by the creep test results on the solder. Near-eutectic $\mathrm{Sn}$-Pb solder has been described as having a power law (Sherby-Dorn) type of behavior that has a form of (Dorn and Mote, 1963): $\dot{\gamma}_{\min }=\mathrm{A}\left(\sigma_{\mathrm{c}}\right)^{\mathrm{n}} \exp _{\mathrm{RT}} \frac{-\mathrm{Q}}{\mathrm{R}_{\mathrm{m}}}$

where $\dot{\gamma}_{\min }$ is the minimum creep strain rate $(1 / \mathrm{sec}), \sigma_{\mathrm{c}}$ is the applied uniaxial stress (Mpa), $R$ is the gas constant, $T$ is the absolute temperature (K), Q is the activation energy ( $\mathrm{kcal} / \mathrm{mol})$, and $\mathrm{A}$ and $\mathrm{n}$ are constants.

The form of equation 5 was based upon tests performed at room temperature and above. For this current work, creep tests were performed over the entire temperature range of interest ranging from $-55^{\circ}$ to $125^{\circ} \mathrm{C}$. The data from these tests are summarized in Figure 4. At temperatures below $0^{\circ} \mathrm{C}$, the solder undergoes power law breakdown and the data can no longer be described by the Sherby-Dorn relationship (a straight line). Under power law breakdown conditions, the sinh law (or Garofalo law) (Garofalo, 1965) equation provides a much better description of the steady state response:

$\gamma_{\min }=\mathrm{A}\left(\sinh \left(\alpha \sigma_{\mathrm{c}}\right)\right)^{\mathrm{n}} \exp \left(\frac{-\mathrm{Q}}{\mathrm{RT}}\right)$

where an $\alpha$ constant term is added to the sinh term. The data in Figure 4 are shown with the sinh law and the fit is excellent. Thus, the sinh law was used as the basis for the kinetic equation in the new viscoplastic model. The constants in equation 2 are determined from the data in Figure 4 by a multivariable regression analysis.

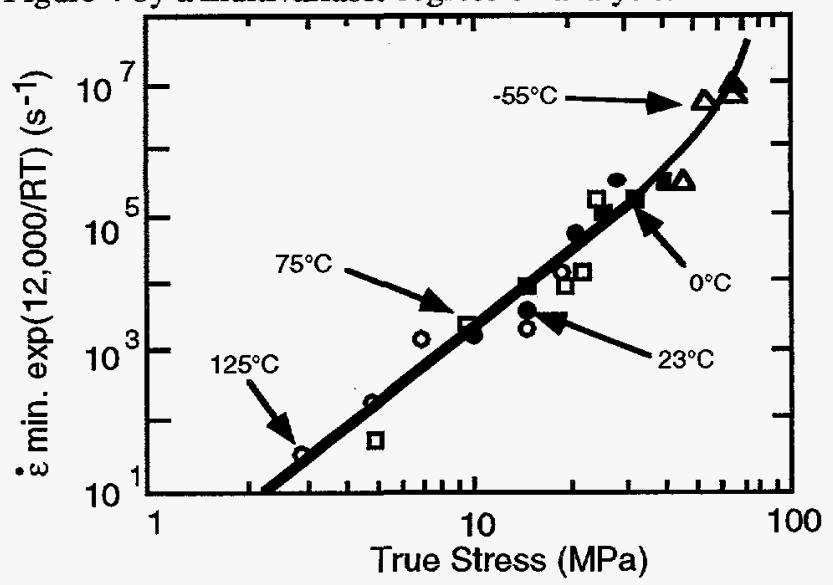

$\dot{\gamma}=1.085 \times 10^{5}\left[\sinh (0.0312 \sigma(\mathrm{MPa})] 3.48 \mathrm{e}^{-(12,001 / \mathrm{kT})} \mathrm{r}^{2}=0.917\right.$

Figure 4 Creep data for $60 \mathrm{Sn}-40 \mathrm{~Pb}$ solder including Garofalo law fit.

Competing hardening and recovery mechanisms are captured by the evolution equations for the internal state variables $\mathbf{c}$ and $\mathbf{B}$. The equation for $\mathrm{c}$ captures isotropic hardening and recovery. Its evolution is given by:

$c=A_{1} \gamma-\left(A_{2} \gamma+A_{3}\right)\left(c-c_{0}\right)^{2}$

where $c_{0}, A_{1}, A_{2}$, and $A_{3}$ are material parameters.

Evolution of the second-order state tensor $B$ for kinematic hardening and recovery is given by: 
$\dot{\mathbf{B}}=\mathrm{A}_{4} \mathrm{~d}^{\text {in }}-\left(\mathrm{A}_{5} \gamma+\mathrm{A}_{6}\right) \sqrt{\left(\frac{2}{3} \mathbf{B}: \mathbf{B}\right) \mathbf{B}}$

where $A_{4}, A_{5}$, and $A_{6}$ are material parameters. For these simulations on solder, the isotropic hardening is not used. The model uses only kinematic relationship because during thermomechanical fatigue the temperature cycling constantly changes the hardening and recovery rates. The isotropic hardening and recovery would be used in conditions where the changes in hardening and recovery due to temperature are minimal such as situations where small changes in temperature are experienced by the solder joints. The constants $A_{1}$ to $A_{6}$ are determined using multivariable regression analysis on the uniaxial stress/strain test data at a variety of temperatures and strain rates for different microstructures.

The reduction in flow resistance with grain coarsening is captured by the scalar state variable $\widehat{C}$. The state variable $\widehat{C}$ is related to the current value of $\lambda$, by:

$\hat{\mathrm{c}}=\mathrm{A}_{7}\left(\frac{\lambda_{0}}{\lambda}\right)^{\mathrm{A}_{8}}$

where $A_{7}$ and $A_{8}$ are positive material parameters. Note that as $\lambda$ increases, $\widehat{E}$ decreases in magnitude which has the effect of reducing the flow resistance of the material. The constant $A_{7}$ in equation 9 is a complex parameter that determines the effectiveness of grain boundaries in raising yield strength. $A_{7}$ is calculated from stress-strain data, and equation 9 and using the initial value of $\widehat{E}$ with the initial value for $\lambda$. The constant $A_{8}$ has been empirically found to be 0.5 for metals (Barrett, et al. 1973).

The unique feature of this methodology is that the microstructure, and its evolution, are inherent features of the model. Aspects of the microstructure are incorporated in the model through the parameter $\lambda$, which represents the average grain size of the solder and damage accumulation in the form of defects. It is based on experimental evidence that suggests that during deformation the diffusion coefficient in or near the grain boundaries increases if the deformation is dominated by grain boundary sliding and rotation (Bhat and Vitovec, 1970; Blackburn and Brown, 1962). There is ample evidence that deformation in near-eutectic $\mathrm{Sn}-\mathrm{Pb}$ is dominated by the sliding and rotation of cells at cell boundaries (Stone and Lee, 1990; Frear et al., 1991). The cell boundaries are the last regions of the joint to solidify and are the coarsest, and therefore the weakest, regions in the joint. Figure 5 shows these boundaries. As strain is applied to the solder, the cells slide and rotate to accommodate the damage. The heterogeneously applied strain at the cell boundaries results in coarsening of those boundaries. This deformation and coarsening can be simulated through the production of excess vacancies in the boundary region. Clark and Alden [1973] proposed a simple model for vacancy mobility in the grain boundaries. We modified the Clark-Alden model for the two-phase $60 \mathrm{Sn}-40 \mathrm{~Pb}$ microstructure to derive relationships for heterogeneous coarsening compatible with the internal state variable constitutive model.

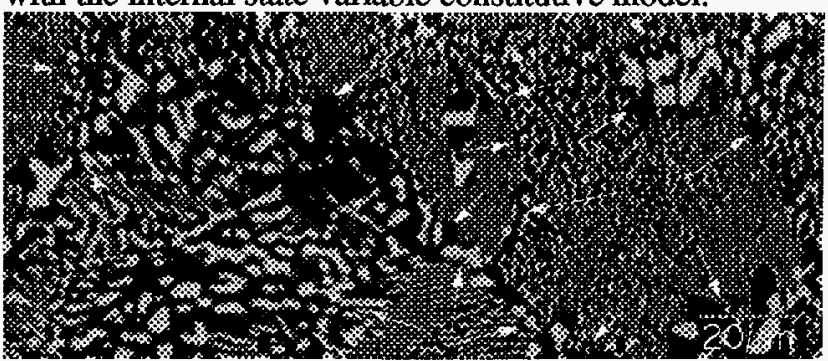

Figure 5 Optical micrograph of an as-solidified solder joint with cell boundaries marked by arrows.

If the production rate of excess vacancies is proportional to the inelastic deformation rate, and the annealing rate of vacancies is proportional to the excess vacancy concentration, then:

$\dot{\mathrm{v}}_{\mathrm{X}}=\mathrm{A}_{9} \dot{\gamma}-\mathrm{v}_{\mathrm{X}} \mathrm{A}_{10}$

where $v_{X}$ is the atomic fraction of vacancies due to imposed strain, and $\mathrm{A}_{9}$ and $\mathrm{A}_{10}$ are material constants.

If $\dot{\gamma}$ is constant then, integration of equation (10) yields $\mathrm{v}_{\mathrm{X}}=\frac{\mathrm{A}_{9}}{\mathrm{~A}_{10}} \dot{\varepsilon}\left(1-\mathrm{e}^{-\mathrm{A}_{10} \mathrm{t}}\right)$

If we assume that diffusion takes place by a vacancy mechanism, the diffusivity, $D$, is:

$\mathrm{D}=\mathrm{D}_{\mathrm{y}}\left(\mathrm{v}_{\mathrm{X}}+\mathrm{v}_{0}\right)$ where $v_{0}$ is the equilibrium vacancy concentration and $D_{v}$ is the diffusion coefficient. For normal grain growth:

$\frac{\mathrm{d} \lambda}{\mathrm{dt}}=-\mathrm{M} \frac{\mathrm{dF}}{\mathrm{dx}}$

where $\lambda$ is grain size and $M$ is the mobility and is related to the diffusivity, $D$, by

$\mathrm{M}=\frac{\mathrm{D}}{\mathrm{kT}}$

and $\frac{\mathrm{dF}}{\mathrm{F}}$ is the gradient of free energy per atom across the $\mathrm{dx}$

boundary and is inversely proportional to the grain size.

Hence:

$\frac{\mathrm{dF}}{\mathrm{dx}}=-\frac{1}{\lambda} \mathrm{A}_{11}$

where $A_{11}$ is a constant. Therefore,

$\frac{\mathrm{d} \lambda}{\mathrm{dt}}=\mathrm{M} \frac{\mathrm{dF}}{\mathrm{dx}}=\left(\frac{\mathrm{D} 1}{\mathrm{kT}_{\lambda}}\right) \mathrm{A}_{11}$

substituting from equation 12 yields:

$\frac{\mathrm{d} \lambda}{\mathrm{dt}}=\frac{\left(\mathrm{v}_{\mathrm{x}}+\mathrm{v}_{0}\right)}{\lambda} \mathrm{A}_{11} \cdot \frac{\mathrm{D}_{\mathrm{V}}}{\mathrm{kT}}$ 
The constant $v_{0}$ can be estimated from Shewman [1963]:

$\mathrm{v}_{0}=\exp \left(\frac{-\Delta \mathrm{H}}{\mathrm{RT}}\right)$

where $\Delta \mathrm{H}$, the activation energy to form a vacancy, is

$11.8 \mathrm{Kcal} / \mathrm{mol}$ [Shewman, 1963] so:

$\mathrm{v}_{0}=\exp \left(\frac{-5.9 \times 10^{3}}{\mathrm{~T}}\right)$

The constant $A_{10}$ depends on the nature of the vacancy sinks. For this model the sinks are assumed to be grain boundaries so that [Clark and Alden, 1973]:

$\mathrm{A}_{10}=\frac{2 \mathrm{D}_{\mathrm{v}}}{\mathrm{L}^{2}}=\frac{2 \mathrm{D}_{0}}{\mathrm{~L}^{2}} \exp \left(\frac{-\Delta \mathrm{H}_{\mathrm{m}}}{\mathrm{RT}}\right)$

where:

$\mathrm{D}_{\mathrm{v}}=\mathrm{D}_{0} 0^{\bullet} \exp \left(\frac{-\Delta \mathrm{H}_{\mathrm{m}}}{\mathrm{RT}}\right), \Delta \mathrm{H}_{\mathrm{m}}$ is the activation energy for vacancy motion $\left(15.7 \mathrm{kcal} / \mathrm{mol}\right.$ [Desorbo, 1959]), $\mathrm{D}_{0}$ is the frequency factor (pre-exponential diffusion coefficient) $(9.7$ $\mathrm{cm}^{2} / \mathrm{sec}$ ), $\mathrm{L}$ is the perpendicular distance from the vacancy source to the sink that is not known quantitatively but is assumed to be $100 \AA$ [Clark and Alden, 1973].

Therefore, $A_{10}$ is:

$A_{10}=\left(1.94 \times 10^{13}\right) \exp \frac{-7.9 \times 10^{3}}{T} /$ second

$A_{9}$ is a constant, such that product $A_{9} \dot{\dot{E}}$ is the rate of vacancy production. An estimated value from Barry and Brown [1964] is $A_{9}=1.7 \times 10^{-5} /$ second. Excess vacancies are generated by inelastic deformation. When inelastic deformation is not being generated, the value of the product $\mathrm{A}_{9} \dot{\gamma}$ becomes 0 .

The constant $\mathrm{A}_{11}$ can be estimated from unstrained grain growth. This follows from the relations for grain growth as a function of time and vacancy concentration. $\overline{\mathrm{D}}^{2}-\overline{\mathrm{D}}_{0}^{2}=\mathrm{Kt}$

and:

$\overline{\mathrm{D}}^{2}-\overline{\mathrm{D}}_{0}^{2}=2 \mathrm{~A}_{11} \mathrm{v}_{0} \mathrm{t} \frac{\mathrm{D}_{\mathrm{v}}}{\mathrm{kT}}$

where $\bar{D}$ is the average grain diameter, $t$ is the time, and

$\mathrm{K}$ is an Arrhenius equation such that $\mathrm{K}=\mathrm{K}_{0} \exp \left(\frac{-\mathrm{Q}}{\mathrm{RT}}\right)$.

Therefore:

$\mathrm{A}_{11}=\frac{\mathrm{K}_{0} \mathrm{e}^{-\mathrm{Q} / \mathrm{RT}}}{2 \mathrm{v}_{0}} \cdot \frac{\mathrm{kT}}{\mathrm{D}_{\mathrm{v}}}$

where $\mathrm{v}_{0}$ comes from equation (17). Substituting for $A_{11}$ in equation 17 provides the change in grain size:

$\frac{\mathrm{d} \lambda}{\mathrm{dt}}=\frac{1}{2 \lambda}\left(\frac{\mathrm{v}_{\mathrm{x}}}{\mathrm{v}_{0}}+1\right) \cdot \mathrm{K}_{0} \mathrm{e}^{-\mathrm{Q} / \mathrm{RT}}$

For near-eutectic $\mathrm{Sn}-\mathrm{Pb}$ solders:

$\mathrm{K}_{0}=8.8 \times 10^{-2} \mathrm{~cm}^{2} / \mathrm{s}$ (Thomas and Birchenall, 1952)
$\mathrm{Q}=23,000 \mathrm{cal} / \mathrm{mol}$ (Thomas and Birchenall, 1952)

$\mathrm{R}=1.98 \mathrm{cal} / \mathrm{mol} \cdot \mathrm{K}$

$\mathrm{V}_{0}=\exp ^{\frac{-5.9 \times 10^{3}}{\mathrm{~T}}}$

$v_{x}=\frac{A_{9}}{A_{10}} \dot{X}\left(1-\mathrm{e}^{-A_{10}} \mathrm{t}\right)$

$\mathrm{A} 9=1.7 \times 10^{-5} / \mathrm{s}$

$A_{10}=\left(1.94 \times 10^{13}\right) \exp \left(\frac{-7.9 \times 10^{3}}{T}\right) / s$

The constants $\mathrm{K}_{0}$ and $\mathrm{Q}$ were derived from the Arrhenius behavior of a dilute solution of $\mathrm{Sn}$ diffusing through a $\mathrm{Pb}$ rich matrix. This scenario was chosen because it is the limiting factor for grain (and phase) growth of the Sn-rich regions. For the $\mathrm{Sn}$-rich grains to grow, $\mathrm{Sn}$ must diffuse into those regions and must do so through the adjacent $\mathrm{Pb}$-rich regions. The activation energy for this process is a factor of two greater than for diffusion of Sn through Sn-rich regions and is therefore the limiting factor for growth.

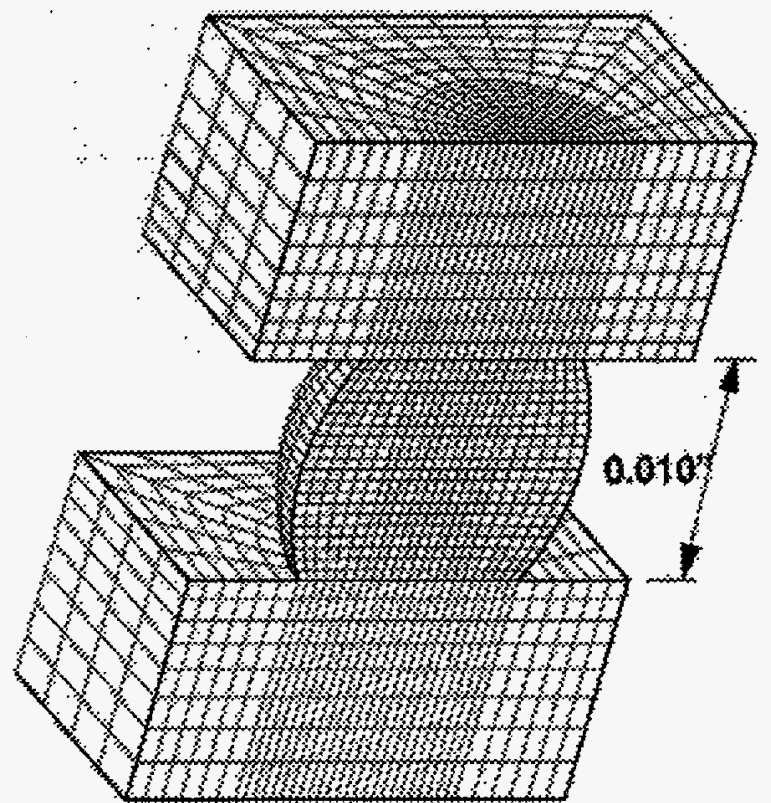

Figure 6 FEM mesh of a solder joint from the simplified test specimen of Figure 3. 


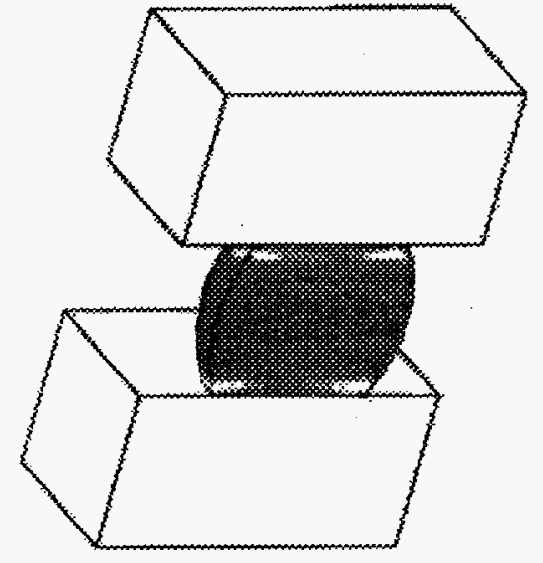

Figure 7 FEM microstructural damage parameter simulation results. Light color corresponds to coarsened regions.

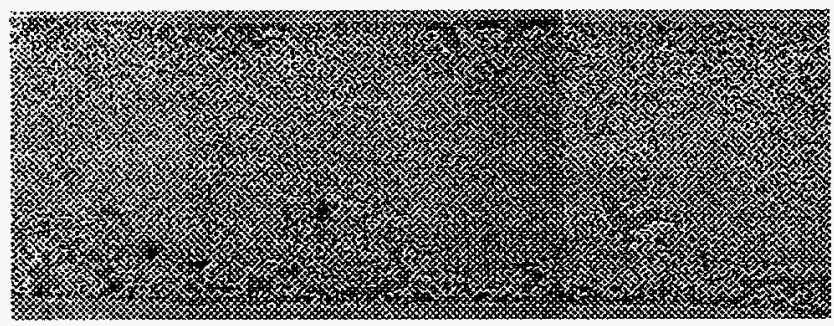

Figure 8 Optical micrograph of a solder joint showing heterogeneous coarsening. (Joint thickness is $0.254 \mathrm{~mm}$.)

\section{MODEL RESULTS}

The constitutive relations described above comprise a time-dependent, viscoplastic microstructurally based constitutive model. This model is a finite element simulation and was implemented into the finite element codes JAC2D (Biffle and Blanford, 1992), JAC3D (Biffle and Blanford, 1993), AND JAS3D (Blanford, 1993).

The internal state variable constitutive model was implemented into JAS3D, a three dimensional finite element simulation, to predict the thermomechanical fatigue response of the solder joints in the simplified thermomechanical fatigue test specimen shown in Figure 3. The simulation consisted of two rigid boards, one fixed the other displaced a total of $10 \%$ in shear over a temperature range of $-55^{\circ}$ to $125^{\circ} \mathrm{C}$. A finite element mesh of this simulation is shown if Figure 6. A plot of the microstructural parameter, $\lambda$, is shown in Figure 7 after a number of thermal cycles. Heterogeneous coarsening developed at regions adjacent to the solder/substrate interface. A cross-section micrograph of a solder joint, after the same number of cycles is shown in Figure 8 . The simulation results that predict the location of the coarsening agree with that observed in the solder joint.
The model was also applied to predict the thermomechanical response of a leadless chip carrier (LCC) solder interconnect. The geometry selected was a one-element thick slice of an LCC solder interconnect shown in Figure 9. This geometry can be considered to be a solder interconnect at the centerline of the LCC package. The substrate was assumed to be a ceramic material with a coefficient of thermal expansion (CTE) of $5 \times 10^{-6} \mathrm{in} / \mathrm{in}^{\circ} \mathrm{C}$. The component was also assumed to be a ceramic material with a CTE of $6 \times 10^{-6} \mathrm{in} / \mathrm{in}^{\circ} \mathrm{C}$. The substrate was assumed to be rigid. A symmetry boundary condition was applied to the front surface and the back surface was free. A uniform, cyclical, time-dependent displacement and temperature history was applied with the magnitude of the applied displacement corresponding to the thermal expansion difference between the component and substrate. The response of the solder interconnect is shown in Figure 10a by the contours of the accumulated plastic strain on the solder interconnect. This plot indicates that the highest magnitude of accumulated plastic strain is under the chip carrier. In Figure 10b, the contours of the computed microstructural parameter are plotted for the solder interconnect. This plot indicates that coarsening occurs at the region of high plastic strain, under the chip carrier. A cross-section micrograph of an LCC solder joint after a number of thermomechanical fatigue cycles is shown in Figure 11. In this micrograph, a crack has formed in the solder joint, under the chip carrier, through the heterogeneous coarsened region. The similarity between the prediction and the observed microstructure validates the simulation methodology showing the coarsening and failure occurring under the chip carrier.

The microstructural parameter can also be used as a metric to predict the lifetime of the solder joint. It is understood that there is an upper limit to the amount of coarsening that can occur in a solder joint before a cracks form in the coarsened regions. It is hypothesized that the $\mathrm{Pb}$ and $\mathrm{Sn}$ grains in the coarsened region grow so large that they can no longer slide and rotate to accommodate the strain which results in the initiation and propagation of cracks. Based on this physical understanding, the microstructural parameter can be used to empirically predict the lifetime of solder interconnects under thermomechanical fatigue conditions. The predicted microstructural parameter, $\lambda$, as a function of number of cycles for $5 \% .10 \%$, and $100 \%$ shear strain is plotted in Figure 12 for the simplified thermomechanical fatigue test specimen. The critical value for $\lambda$ was empirically chosen for the $10 \%$ shear strain sample at $\lambda=14.5$ (the failure limit). Table I lists the predicted number cycles to failure using this limiting value of $\lambda$ versus those found experimentally for the three levels of shear strain. The predicted values come 
very close to the observed which helps to validate the methodology.

Table I Damage Parameter Failure Limit

\begin{tabular}{|c|c|c|c|}
\hline Strain & $\lambda$ & $\begin{array}{c}\mathbf{N}_{\mathrm{f}} \\
\text { Experimental }\end{array}$ & $\begin{array}{c}\mathbf{N}_{\mathrm{f}} \\
\text { Predicted }\end{array}$ \\
\hline \hline $5 \%$ & 14.5 & 415 & 425 \\
\hline $10 \%$ & 14.5 & 225 & 220 \\
\hline $100 \%$ & 14.5 & 65 & 70 \\
\hline
\end{tabular}

\section{CONCLUSIONS}

The advantages of this predictive methodology are that: (a) it incorporates the behavior that strongly affects solder joint reliability (time dependent deformation and microstructural evolution), (b) microstructural evolution and the strain concentrations that result from the evolution are accounted for, (c) the material constants in the simulations are based upon straightforward experimental tests, (d) extensive lifetime data are not needed to empirically predict life because the methodology is based upon fundamental microstructural behavior, and (e) the results can be easily verified experimentally. The focus for the development of this model was that it be based upon fundamental materials behavior and that the constants present in the model have a true physical significance that could be quantified experimentally.

\section{ACKNOWLEDGMENTS}

This work was performed at Sandia National Labs which supported by the United States Department of Energy under Contract DE-AC04-94AL85000. Sandia is a multiprogram laboratory operated by Sandia Corporation, a Lockheed Martin Company, for the United States Department of Energy.

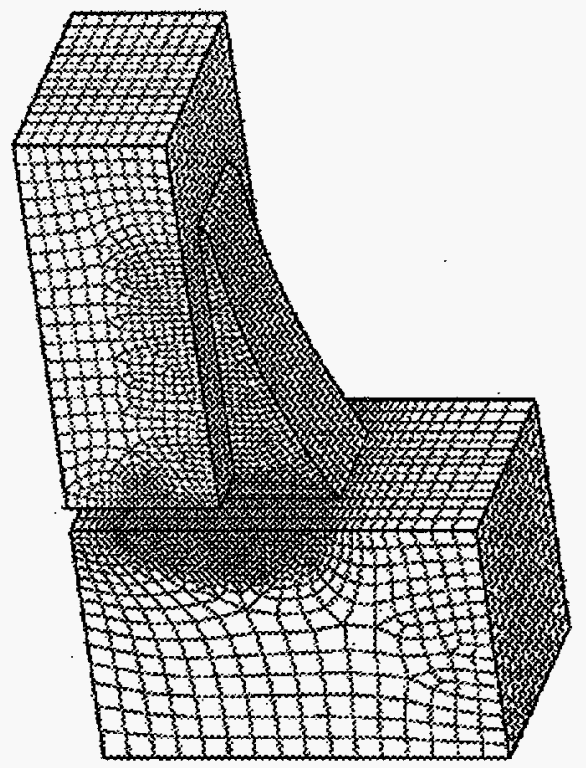

Figure 9 FEM mesh of an LCC solder joint.

a)

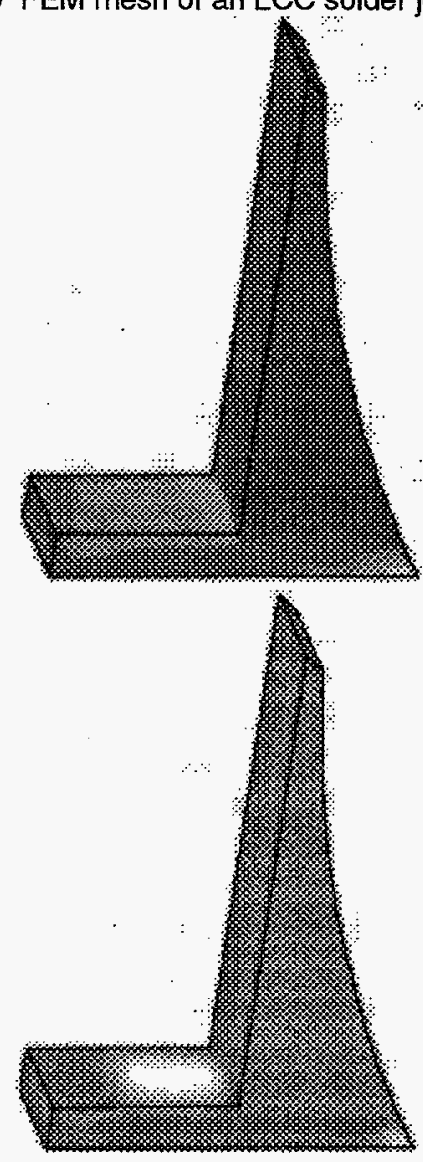

Figure 10 a) Accumulated plastic strain and b)microstructural damage parameter.

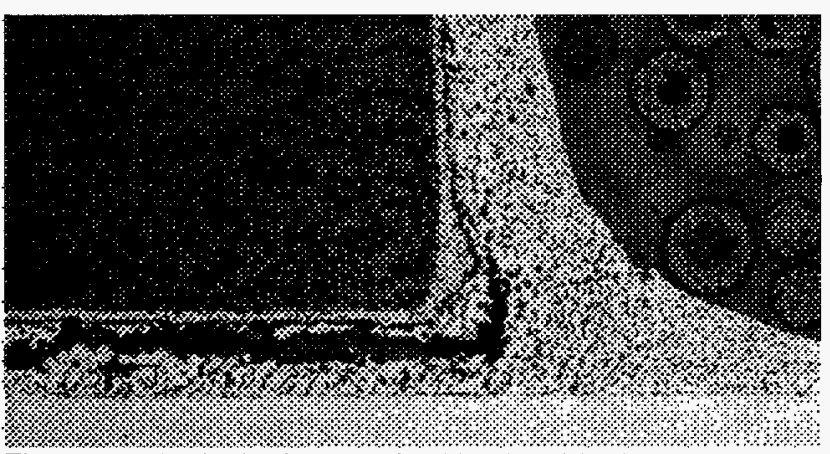

Figure 11 Optical micrograph of LCC solder joint after thermomechanical fatigue.

\section{REFERENCES}

Akay, J. U., Tong, Y., Payday, 1993, "Thermal Fatigue Analysis of an SMT Solder Joint Using FEM Approach", J. Microcircuits and Electron. Packaging, vol. 116, pp. 79-88. 
Barrett, C. R., Nix, W. D., Tetelman, A. S., 1973, The Principles of Engineering Materials, Prentice-Hall, Inc, Englewood Cliffs, NJ, p. 267.

Barry, B. E., Brown, A. F., 1964, Acta Met., vol. 12, p. 209.

Bhat, T. A, Vitovec, F. H., 1970, J. Inst. Met, vol. 98, p. 95.

Biffle, J. H., Blanford, M. L., 1993, “JAC3D - A Two-D FE Computer Program for the Non-Linear Quasi-Static Response of Solids with the Conjugate Gradient Method", SAND87-1305, Sandia National Laboratories.

Biffle, J. H., Blanford, M. L., 1994, "JAC2D - A Two-D FE Computer Program for the Non-Linear Quasi-Static Response of Solids with the Conjugate Gradient Method", SAND93-1891, Sandia National Laboratories.

Blackburn, D A., Brown, A. F., 1962-63, J. Inst. Met., vol. 91 p. 106.

Blanford, M. L., 1993, "JAS3D - A Multi-Strategy Iterative Code for Solid Mechanics Analysis - Release 1.3", Sandia National Laboratories.

Busso, E. P., Kitano, M., Kumazawa, T., 1992, “A Visco-Plastic Constitutive Model for 60/40 Tin-Lead Solder Used in IC Package Joints", J. Engr. Mater. Tech., vol. 114, 1992.

Clark, M. A., Alden, T. H., 1973, "Deformation Enhanced Grain Growth in a Superplastic Sn-1\%Bi Alloy", Acta Met., vol. 21, p. 1195.

Desorbo, W., 1959, Bull. Amer. Phys. Soc. (Series II), vol. 4, p. 149.

Dorn, J. E., Mote, J. D., 1963, "Physical Aspects of Creep", High Temperature Structures and Materials, Proc. 3rd Symp on Naval Structural Mechanics, New York, pp. 95-168.

Frear, D. R., 1989, "Thermomechanical Fatigue of Solder Joints: A New Comprehensive Test Method" IEEE Comp. Hybrids. Man. Tech., CHMT-12, pp. 492-501.

Frear, D. R., Jones, W. B., Kinsman, K. R., 1991, Solder Mechanics: A State of the Art Assessment TMS Publications, Warrendale, PA, pp. 191-237.

Frear, D. R., Rashid, M. M., Burchett, S. N., 1993, "Microstructurally Based TMF Lifetime Model of Solder Joints for Electronic Applications", Reliability, Stress Analysis and Failure Prevention, DE-vol. 55, ASME, R. J. Schaller, ed., pp. 277-287.

Frost, H. J., Howard, R. T., 1990, "Creep Fatigue Modeling for Solder Joint Reliability Predictions Including the Microstructural Evolution of the Solder", IEEE Trans. Components Hybrids and Manufacturing Tech., vol. 13, pp. 727-735.

Garofalo, F. A., 1965, Fundamentals of Creep and CreepRupture in Metals, The MacMillan Company, New York, NY, pp. 51-55.
Guo, Z., Sprecher, A. F., Conrad, J., 1992, "Plastic Deformation Kinetics of Eutectic Pb-Sn Solder Joints in Monotonic Loading and Low-Cycle Fatigue", J. Electron. Packaging, vol. 114.

Hacke, P., Sprecher, A. F., Conrad, H., 1993, "Computer Simulation of Thermomechanical Fatigue of Solder Joints Including Microstructural Coarsening", ASME J. Electron. Packaging, vol. 115, pp. 153-158.

Iannuzzelli, R. J., Pitarresi, J. M., Prakash, V., 1996, "Solder Joint Reliability Prediction by the Integrated matrix Creep Method", J. Electron. Packaging, vol. 118, pp. 55-61.

Knecht, S., Fox, L. R., 1990, "Constitutive Relation and Creep-Fatigue Life Model for Eutectic Tin-Lead Solder", IEEE Trans. Components Hybrids and Manufacturing Tech., vol. 13, pp. 424-433.

Ling, S., Dasgupta, A., 1996, "A Nonlinear Multidomain Stress-Analysis Method for Surface-Mount Solder Joints", J. Electron. Packaging, vol. 118, pp. 72-79.

Pan, T.-Y., Winterbottom, W. L., 1990, “Thermal Cycling Induced Plastic Deformation in Solder Joints", ASME Winter Annual Meeting, Dallas, TX.

Shewman, P. G., Diffusion in Solids, McGraw-Hill (1963).

Stone, D. S., Lee, S. M., 1990, SMART Conference. Syed, A. R., 1995, "Creep Crack-Growth Prediction of Solder Joints During Temperature Cycling: An Engineering Approach", J. Electron. Packaging, vol. 117, pp. 116-122.

Thomas, D. E., Birchenall, C. E., 1952, AIME Trans. Journal of Metals, pp. 867-873.

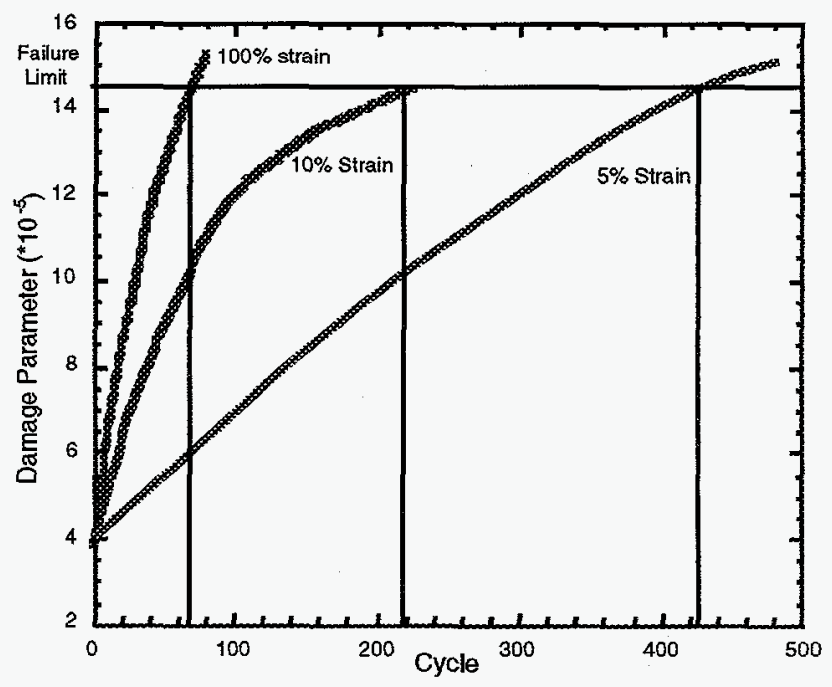

Figure 12 Damage parameter as a function of time for various shear strain values. 